\title{
Effect of Cerium Content on the Evolution of Inclusions and Formation of Acicular Ferrite in Ti-Mg-Killed EH36 Steel
}

\author{
Zhen Liu ${ }^{1}$, Bo Song ${ }^{1, *}$, Zhanbing Yang ${ }^{1}$, Xiaokang Cui ${ }^{1}$, Longfei Li ${ }^{1}$, Lei Wang ${ }^{1}$ \\ and Zirui Song ${ }^{2}$ \\ 1 School of Metallurgical and Ecological Engineering, University of Science and Technology Beijing, \\ Beijing 100083, China; liuzhen_ustb@163.com (Z.L.); yangzhanbing@ustb.edu.cn (Z.Y.); \\ cuixiaokang126@126.com (X.C); aifei_0105@126.com (L.L.); wanglei_ustb020@163.com (L.W.) \\ 2 College of Engineering, Boston University, Boston, MA 02215, USA; songzirui1996@sina.com \\ * Correspondence: songbo@metall.ustb.edu.cn; Tel.: +86-010-6233-2208
}

Received: 4 June 2020; Accepted: 26 June 2020; Published: 29 June 2020

\begin{abstract}
Ce has been widely used in oxide metallurgy for modifying inclusions and refining microstructure. Effect of Ce contents on the evolution and characteristics of non-metallic inclusions and the formation of acicular ferrite (AF) in Ce-treated Ti-Mg-killed EH36 steel was investigated. The results showed that the main type of inclusions in Ti-Mg deoxidized steel was $\mathrm{MgO} \cdot \mathrm{Al}_{2} \mathrm{O}_{3}-\mathrm{MnS}$. After $0.014 \%, 0.024 \%$ and $0.037 \%$ Ce were added into the steels, dominant inclusions became $\mathrm{CeAlO}_{3}-\mathrm{MgO}-\mathrm{MnS}, \mathrm{Ce}_{2} \mathrm{O}_{2} \mathrm{~S}-\mathrm{MgO}-\mathrm{MnS}$ and $\mathrm{Ce}_{2} \mathrm{O}_{2} \mathrm{~S}-\mathrm{MnS}$, respectively. The precipitation of pure $\mathrm{MnS}$ was suppressed in the steel with $0.024 \% \mathrm{Ce}$, while the number density of total inclusions increased significantly in the steel with $0.037 \% \mathrm{Ce}$, causing the inclusions distributing densely. Ce addition refined the microstructure of tested steels by promoting AF formation and polygonal ferrite distributing evenly. Dispersive distribution, low lattice mismatch against $\alpha$-Fe, as well as lower number density of pure MnS caused the highest number density of effective inclusions (nucleus of AF formation) in $0.024 \%$ Ce-treated steel.
\end{abstract}

Keywords: Ce content; inclusions; evolution; acicular ferrite; EH36 steel

\section{Introduction}

The development of the shipbuilding industry and the application of high heat input welding (HHIW) have put forward higher requirements for the performances of ship plate steel featuring low carbon, high manganese and micro-alloying [1,2]. EH36, the most widely used ship plate steel, has to meet the requirements of strength, toughness and weldability. However, the typical grain-refining particles in EH36 steel, AlN and TiN, will dissolve and lose their pinning effect during HHIW process, causing the microstructure in heat affected zone (HAZ) coarsening rapidly and HAZ toughness decreasing significantly [3,4]. "Oxide metallurgy", using fine dispersed non-metallic inclusions or precipitates, such as pure oxides, oxy-sulfides and complex inclusions, to induce acicular ferrite (AF) nucleation and pin austenite grains, refines the microstructure of HAZ [5,6]. AF, known for its high dislocation density $\left(10^{6}-10^{8} \mathrm{~mm}^{-2}\right)$ and chaotic crystallographic orientation retards the propagation of cleavage cracks in steels and improves HAZ toughness [7].

$\mathrm{Mg}$ addition has been reported to promote the formation of AF in EH36 steel [8-10]. Mg treatment refines the inclusions in the steel, increases the number density of inclusions and promotes MnS precipitation on oxide inclusions, which is conducive to induce the nucleation of AF. The typical inclusions in Ti-killed ship plate steel, such as $\mathrm{Ti}_{2} \mathrm{O}_{3}$, are also favorable for the formation of AF due to the existence of a manganese-depleted zone (MDZ) around the inclusions [11]. Furthermore, because Ti 
is a common element for shipbuilding steel, complex deoxidization with $\mathrm{Ti}$ and $\mathrm{Mg}$ has attracted extensive research attentions [12-15]. Crystallization of Ti and Mg oxides in the melts (1873 K) starts immediately when Ti and Mg are added into steel according to Equations (1) to (5) [16,17].

$$
\begin{gathered}
2[\mathrm{Ti}]+3[\mathrm{O}]=\mathrm{Ti}_{2} \mathrm{O}_{3}(s), \Delta G^{\theta}=-1,072,827+346.0 T, \mathrm{~J} \cdot \mathrm{mol}^{-1} \\
{[\mathrm{Ti}]+2[\mathrm{O}]=\mathrm{TiO}_{2}(s), \Delta G^{\theta}=-675,720+224.6 \mathrm{~T}, \mathrm{~J} \cdot \mathrm{mol}^{-1}} \\
3[\mathrm{Ti}]+5[\mathrm{O}]=\mathrm{Ti}_{3} \mathrm{O}_{5}(s), \Delta G^{\theta}=-1,392,344+407.7 \mathrm{~T}, \mathrm{~J} \cdot \mathrm{mol}^{-1} \\
{[\mathrm{Mg}]+[\mathrm{O}]=\mathrm{MgO}(\mathrm{s}), \Delta G^{\theta}=-732,950+240.28 \mathrm{~T}, \mathrm{~J} \cdot \mathrm{mol}^{-1}} \\
{[\mathrm{Mg}]+2[\mathrm{Al}]+4[\mathrm{O}]=\mathrm{MgO} \cdot \mathrm{Al}_{2} \mathrm{O}_{3}(\mathrm{~s}), \Delta \mathrm{G}^{\theta}=-1,620,910+451.16 \mathrm{~T}, \mathrm{~J} \cdot \mathrm{mol}^{-1}}
\end{gathered}
$$

On one hand, the number density of Ti-Mg complex deoxidization inclusions is higher than that of single $\mathrm{Mg}$ deoxidization inclusions. Ti-Mg-O + MnS, the common inclusions in Ti-Mg-killed steels, are in favor of AF nucleation due to the existence of MDZ. On the other hand, the size of inclusions in Ti-Mg deoxidized steels are finer than that of inclusions in single Ti deoxidized steels because Ti oxide inclusions nucleates on $\mathrm{Mg}$-containing inclusions heterogeneously. As a result, the deoxidization of Ti-Mg exhibits good potential for the formation of AF than that of Ti or Mg alone [12-14]. However, because the desulphurization ability of $\mathrm{Ti}$ or $\mathrm{Mg}$ is not strong enough, it is difficult to avoid a certain amount of pure MnS in Ti-Mg-killed steels, which reduces the probabilities of AF nucleation on inclusions $[9,18]$. Ce, as a strong desulfurizer, has been widely used in oxide metallurgy. Ce modifies $\mathrm{MnS}$ into $\mathrm{Ce}_{2} \mathrm{O}_{2} \mathrm{~S}$ in SS400 steel [19]. This kind of inclusions is the nucleation sites of AF due to the low lattice mismatch between the inclusions and $\alpha$-Fe [20]. Meanwhile, Ti nitrides, $\mathrm{Mg}$ and Ce oxides as well as the Ce oxy-sulphide coexisted in the Ti-Mg-Ce-(S, O, N) system. These inclusions have the potential to promote the formation of AF. Therefore, Ti-Mg-Ce complex deoxidization is expected to have a better effect on promoting AF nucleation than that of Ti-Mg complex deoxidization. Meanwhile, the effect of $\mathrm{Mg}$ on refining inclusions makes up for the deficiency of Ce-containing inclusions caused by their aggregated tendency in molten steel [21]. As a result, the fine and dispersed inclusions with good potency of AF nucleation will be obtained in Ti-Mg-Ce complex deoxidized steels, which is of great significance for the improvement of the weldability of ship plate steels, especially EH36, one of the most urgent steels for weldability under the background of HHIW.

However, no systematic work has been reported about the effect of Ti-Mg-Ce treatment on AF formation in EH36 steel, and the evolution of inclusions in the process of complex deoxidization has not been fully understood. Therefore, in this study, the effect of Ce content on the evolution and characteristics of inclusions in Ti-Mg-killed EH36 steel was investigated. The potency of various inclusions for the AF nucleation and its mechanism were explored. It is expected that the current study provides a basis for the control of potential inclusions working as the nucleus of AF nucleation in shipbuilding steels.

\section{Materials and Methods}

Based on Chinese standard GB 712-2011, EH36 steel (composition/\%: C 0.06, Si 0.24, Mn 1.44, $\mathrm{P} 0.01, \mathrm{~S} 0.008, \mathrm{O} 0.008, \mathrm{~N} 0.004, \mathrm{Al} 0.005, \mathrm{~V}+\mathrm{Nb}+\mathrm{Ti}<0.01$ ) was melted in a vacuum induction furnace as a raw material. Melting and solidification experiments of tested steels were then carried out in a molybdenum resistance furnace with an accuracy of temperature controlling $\pm 2 \mathrm{~K}$ under a purified argon atmosphere. About $500 \mathrm{~g}$ EH36 steel charge in a corundum crucible $(\phi 45 \times 120)$ was heated to $1873 \mathrm{~K}$ and held for $10 \mathrm{~min}$ to homogenize composition and temperature. In consideration of being close to actual production, the melts were sequentially deoxidized by Al wire (99.99\% $\mathrm{Al}), \mathrm{Ni}-\mathrm{Mg}$ alloy (14\% Mg), metal $\mathrm{Ti}(99.99 \%)$ and Ce (99.8\%). The alloys were wrapped by an iron sheet and immersed in the molten steels to complete the addition. To analyze the evolution of inclusions during melting process, melt sampling was carried out by a quartz tube according to Figure 1. Samples taken from 
points 3 and 4 were named as A-1 and A-2, separately, while those taken from point 7 after treated by $0,0.014 \%, 0.024 \%$ and $0.037 \%$ Ce were named as B-1, B-2, B-3 and B-4, respectively. The steel charge was then taken out and quenched to room temperature after being cooled to $1373 \mathrm{~K}$ in the furnace. The order of adding deoxidizers, sampling time and cooling processes are shown in Figure 1. Table 1 is the chemical composition of tested steels with the corresponding detection methods in its footer.

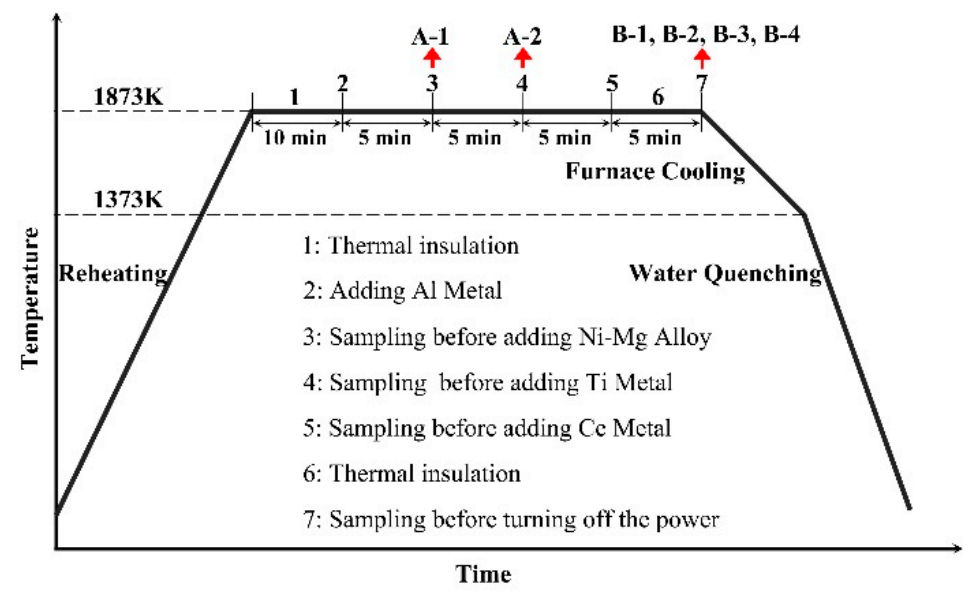

Figure 1. Schematic diagram of the order of adding alloys, sampling time and cooling processes.

Table 1. Chemical composition of tested steels $/ \mathrm{wt} \%$.

\begin{tabular}{ccccccccccccc}
\hline No. & $\mathbf{C}^{\mathbf{1}}$ & $\mathbf{M n}^{\mathbf{2}}$ & $\mathbf{S i}^{\mathbf{2}}$ & $\mathbf{P}^{\mathbf{2}}$ & $\mathbf{S}^{\mathbf{1}}$ & $\mathbf{A l}^{\mathbf{2}}$ & $\mathbf{M g}^{2}$ & $\mathbf{T i}^{\mathbf{2}}$ & $\mathbf{C e}^{3}$ & $\mathbf{T . O}^{\mathbf{1}}$ & $\mathbf{N}^{\mathbf{4}}$ & $\mathbf{F e}$ \\
\hline$\# 1$ & 0.053 & 1.46 & 0.24 & 0.01 & 0.0082 & 0.0087 & 0.0044 & 0.016 & 0 & 0.0040 & 0.0037 & Bal. \\
$\# 2$ & 0.053 & 1.44 & 0.24 & 0.01 & 0.0081 & 0.0086 & 0.0028 & 0.013 & 0.014 & 0.0055 & 0.0038 & Bal. \\
$\# 3$ & 0.053 & 1.46 & 0.24 & 0.01 & 0.0082 & 0.0086 & 0.0029 & 0.014 & 0.024 & 0.0047 & 0.0037 & Bal. \\
$\# 4$ & 0.052 & 1.46 & 0.24 & 0.01 & 0.0083 & 0.0088 & 0.0028 & 0.013 & 0.037 & 0.0041 & 0.0034 & Bal. \\
\hline
\end{tabular}

${ }^{1}$ Infrared Spectroscope (IR); ${ }^{2}$ Inductively Couple Plasma Atomic Emission Spectrometric (ICP-AES); ${ }^{3}$ Inductively Couple Plasma Mass Spectrometry (ICP-MS); ${ }^{4}$ Inert Gas Fusion Thermal Conductivity Method (IGF-TC).

For consistency, the size distribution of inclusions in the samples was analysed by the point counting method, while automatic scanning electron microscope equipped with energy dispersive spectrometer (SEM-EDS) was only used for analyzing the composition of inclusions. The samples $(\phi 10 \mathrm{~mm} \times 5 \mathrm{~mm})$ cut from half of the radius of the ingots were mechanically grounded, polished and etched for 10-12 s in 4 vol\% nital for metallographic observation. Before and after etching, 100 photos were taken at 1000 times magnification by an optical microscope (OM) to quantify the size of total inclusions and effective inclusions in the steels, respectively. The point counting method was used to count the number of inclusions in the OM images with the help of the image processing software, ImageJ. The number density of inclusion was calculated by Equation (6).

$$
n=\frac{N_{\text {Total }}}{A_{\text {Total }}}
$$

where, $n, N_{\text {Total }}$ and $A_{\text {Total }}$ refer to number density of inclusions, total number of inclusions in photos and total area of photos, respectively.

Automatic SEM-EDS (Zeiss EVO18 SEM coupled with Oxford INCA energy-dispersive X-ray spectroscope (EDS) (Carl Zeiss AG, Oberkochen, Germany) was used to analyze pure MnS in the as-cast samples. The scanning area and minimum size of inclusions were set to $7.44 \mathrm{~mm}^{2}$ and $0.5 \mu \mathrm{m}$, respectively. More than 500 inclusions were analyzed in each sample. The composition of inclusions was analyzed by SEM (FEI Navo Nano 650, FEI Co., Hillsboro, OR, USA) equipped with EDS (EDAX ELEMENT, EDAX Inc., Berwyn, PA, USA). The Scheil-Gulliver cooling model coupled with FactPS, FToxid, FSstel and self-created CEOS databases in FactSage software (version 
7.0, CRCT-ThermFact Inc., Montreal, QC, Canada and GTT-Technologies, Herzogenrath, Germany) was used to calculate the formation of inclusions in tested steels. The CEOS database was created based on the Equation (7) [22]. The distribution of grain boundaries in tested steels was analyzed by electron back-scatter diffraction techniques (EBSD, Zeiss EVO 18 SEM equipped with Oxford instrument Nordlys Nano detector, Oxford Instruments plc, Abingdon, UK).

$$
\Delta G_{f, e_{2} \mathrm{O}_{2} S}^{\theta}=-1.74 \times 10^{6}+7.25 \times 10^{2} \mathrm{~T}-1.18 \times 10^{-2} \mathrm{~T}^{2}+1.05 \times 10^{6} \mathrm{~T}^{-1}-1.25 \times 10^{5} \mathrm{~T} \ln \mathrm{T}, \mathrm{J} \cdot \mathrm{mol}^{-1}
$$

\section{Results and Discussion}

\subsection{Composition, Size and Number Density of Total Inclusions}

The number density of pure MnS detected by Automatic SEM-EDS in the as-cast samples is shown in Figure 2a. As the content of Ce increased in the steels, the number density of pure MnS was reduced obviously. The value decreased from about $30 \mathrm{~mm}^{-2}$ in the Steel \#1 and \#2 to about $12 \mathrm{~mm}^{-2}$ in the Steel \#3 to only about $8 \mathrm{~mm}^{-2}$ in the Steel \#4 with the increase of Ce content.
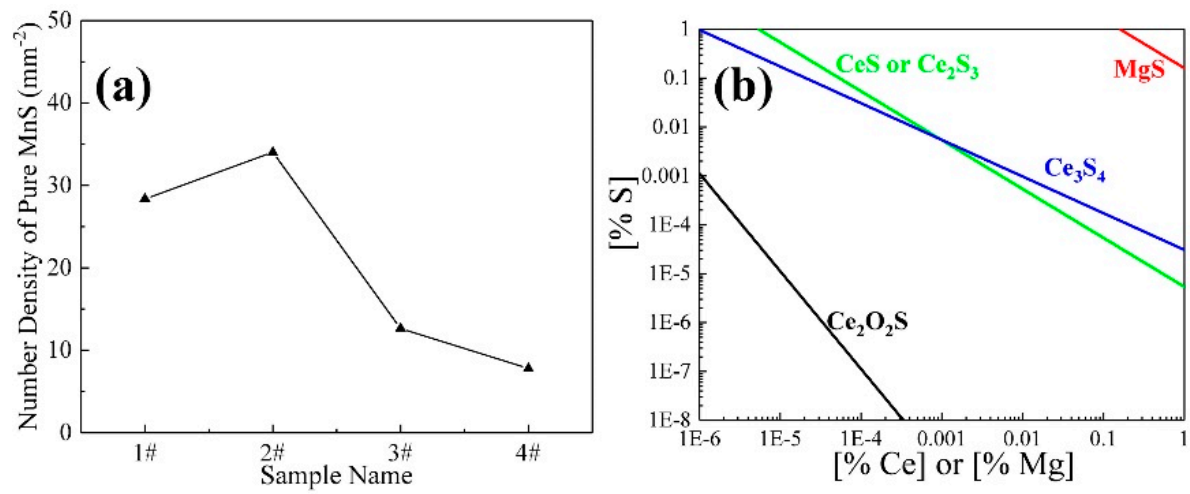

Figure 2. (a) Number density of pure MnS in the as-cast samples; (b) desulphurization curves of $\mathrm{Mg}$ and $\mathrm{Ce}$ in $1873 \mathrm{~K}$ with $0.004 \%$ [O].

Desulphurization capacities of $\mathrm{Mg}$ and Ce were calculated as shown in Figure 2b. A detailed calculation is provided in the Supplementary Materials. It clearly showed that as the Ce content in the melt increased, especially when $\mathrm{Ce}_{2} \mathrm{O}_{2} \mathrm{~S}$ formed, the content of $\mathrm{S}$ decreased rapidly. However, the $\mathrm{S}$ content in the $\mathrm{Mg}$-treated melt changed insignificantly. Ce is a stronger desulfurizer than $\mathrm{Mg}$. The content of $S$ in the melts treated by Ce decreased obviously, causing the number density of pure MnS to decline in the steels.

Thermodynamic calculation results of inclusions in the final quenched steels are shown in Figure 3. It clearly showed that the initial precipitation temperature and mass fraction of MnS decreased when the content of Ce reached $0.024 \%$. The percentage of MnS in Steel \#4 was minimum among the steels as shown in Figure 3d. The calculation results are basically consistent with the experimental results. Moreover, the addition of $\mathrm{Ce}$ also had a great influence on the types of oxides. $\mathrm{MgAl}_{2} \mathrm{O}_{4}$ and $\mathrm{MgO}$ were the main oxides in Steel \#1 shown in Figure 3a. After $0.014 \%$ and $0.024 \%$ Ce were used in the steels, the primary oxides in Steel \#2 and \#3 became $\mathrm{CeAlO}_{3}$ and $\mathrm{Ce}_{2} \mathrm{O}_{2} \mathrm{~S}$, respectively. The ratio of $\mathrm{Ce}_{2} \mathrm{O}_{2} \mathrm{~S}$ obviously increased after $0.037 \%$ Ce was used in Steel \#4. TiN precipitated in the cooling process and its content only had a minor change with the increase of Ce content. 

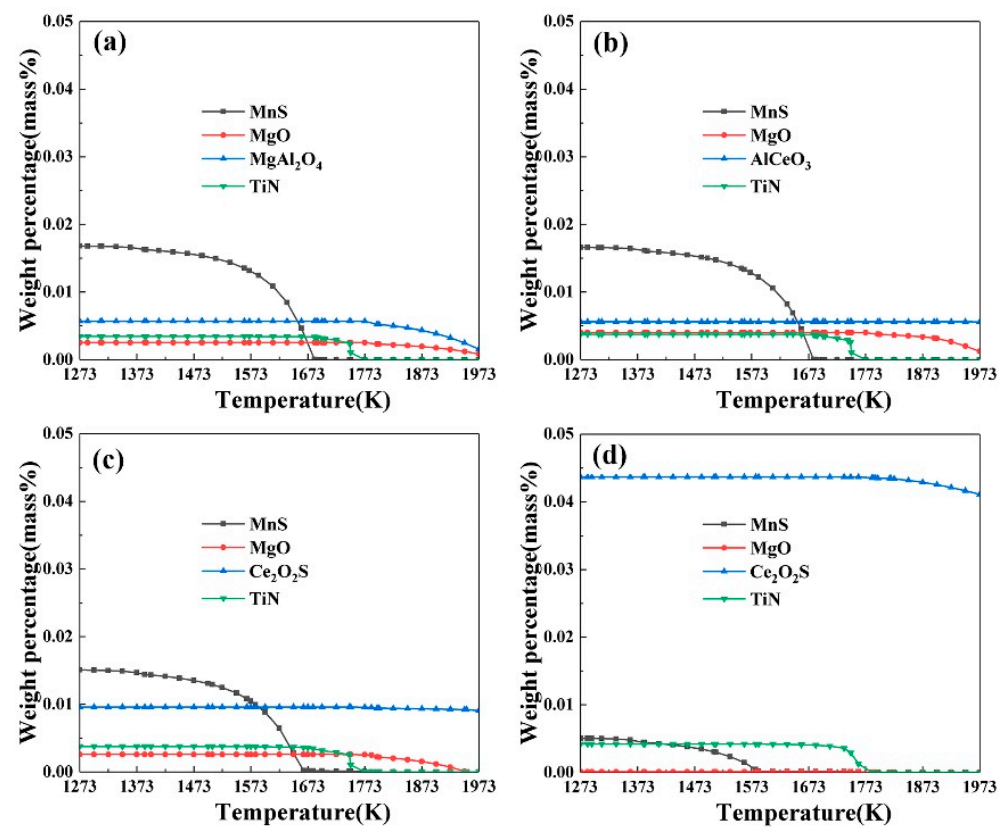

Figure 3. Thermodynamic calculation results of the as-cast steels. (a) \#1 (Ce-free); (b) \#2 (0.014\% Ce); (c) \#3 (0.024\% Ce); (d) \#4 (0.037\% Ce).

The characteristics of inclusions in as-cast samples are related to those in the melts. Therefore, it is essential to study the evolution of inclusions in the melts. EDS results showed that before the addition of $\mathrm{Mg}$, the main inclusions in the melt was $\mathrm{Al}_{2} \mathrm{O}_{3}$ (Figure 4a). With $\mathrm{Mg}$ treatment, the main inclusions in the melt changed to $\mathrm{MgO} \cdot \mathrm{Al}_{2} \mathrm{O}_{3}$ (Figure $4 \mathrm{~b}$ ).
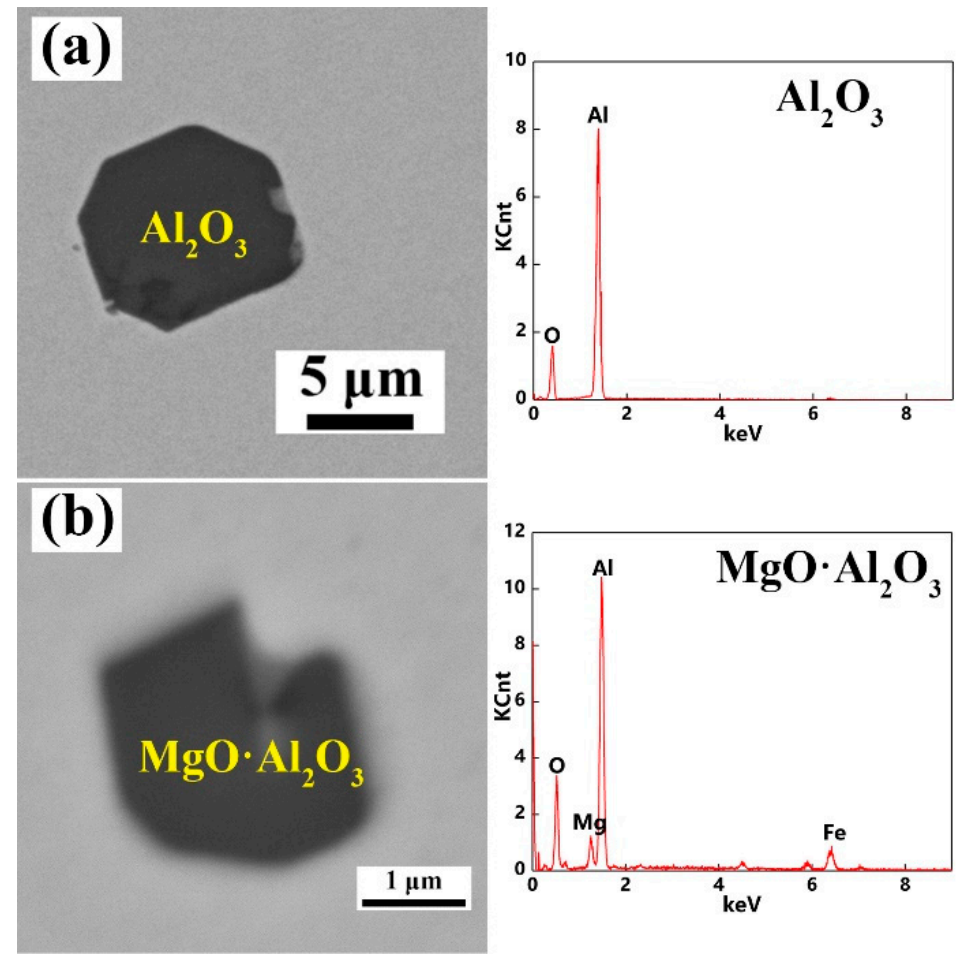

Figure 4. Main inclusions in the melts. (a) A-1 and (b) A-2.

Further addition of Ti in the melt of B-1 did not influence the composition of inclusions as shown in Figure 5(a2). The Ce addition changed the features of inclusions, especially for the distribution 
and composition. Firstly, as the Ce content increased from 0 to $0.024 \%$, the inclusions in the melts were distributed evenly (Figure $5(\mathrm{a} 1, \mathrm{~b} 1, \mathrm{c} 1)$, while they tended to aggregate when Ce content reached $0.037 \%$ (Figure 5(d1)). Secondly, with the increase of Ce content in the melts, the types of inclusions changed from single-phase $\mathrm{MgO} \cdot \mathrm{Al}_{2} \mathrm{O}_{3}$ to multi-phase $\mathrm{CeAlO}_{3} / \mathrm{Ce}_{2} \mathrm{O}_{2} \mathrm{~S}-\mathrm{MgO}$ to single-phase $\mathrm{Ce}_{2} \mathrm{O}_{2} \mathrm{~S}$ (Figure 5(a2,b2,c2,d2)). Ren and Zhang's work indicated that when the content of oxygen was less than $100 \mathrm{ppm}$ and that of sulphur was over $10 \mathrm{ppm}$, formation sequence of inclusions containing Ce in $\mathrm{Mn}$-Si-Al-killed steel was from $\mathrm{CeAlO}_{3}$ to $\mathrm{Ce}_{2} \mathrm{O}_{2} \mathrm{~S}$ [23]. The current study was consistent with the previous literature.

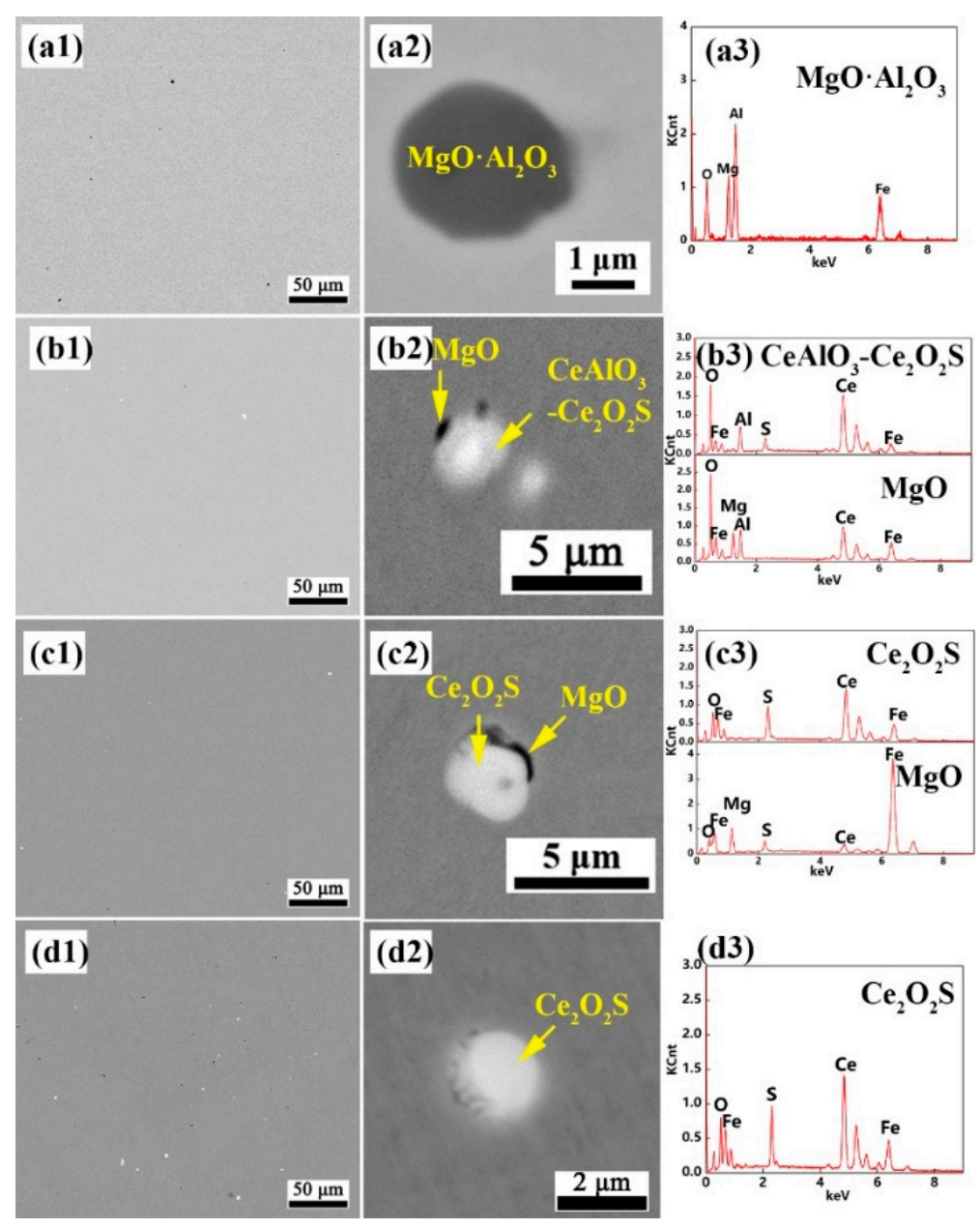

Figure 5. Typical inclusions in the melts. (a1-a3) B-1 (Ce-free); (b1-b3) B-2 (0.014\% Ce); (c1-c3) B-3 $(0.024 \%$ Ce) and (d1-d3) B-4 (0.037\% Ce).

For the distribution of inclusions in the as-cast samples (Figure $6(\mathrm{a} 1, \mathrm{~b} 1, \mathrm{c} 1, \mathrm{~d} 1)$ ), it was similar to that in the melts. Dispersed inclusions were observed in Steel \#1, \#2 and \#3 and the inclusions in the Steel \#4 distributed densely. The composition of inclusions in the as-cast samples (Figure 6(a2-d2, a3-d3)) differed from those in the molten steels. Owing to the precipitation of MnS during cooling process, the main types of inclusions in Steel \#1, \#2, \#3 and \#4 were $\mathrm{MgO} \cdot \mathrm{Al}_{2} \mathrm{O}_{3}-\mathrm{MnS}, \mathrm{CeAlO}_{3}-\mathrm{MgO}-\mathrm{MnS}$, $\mathrm{Ce}_{2} \mathrm{O}_{2} \mathrm{~S}-\mathrm{MgO}-\mathrm{MnS}$ and $\mathrm{Ce}_{2} \mathrm{O}_{2} \mathrm{~S}-\mathrm{MnS}$, respectively. In addition, TiN-containing inclusions were also found in the steels shown in Figure 6(e1,e2). The experimental results were consistent with the calculating ones shown in the Figure 3. 


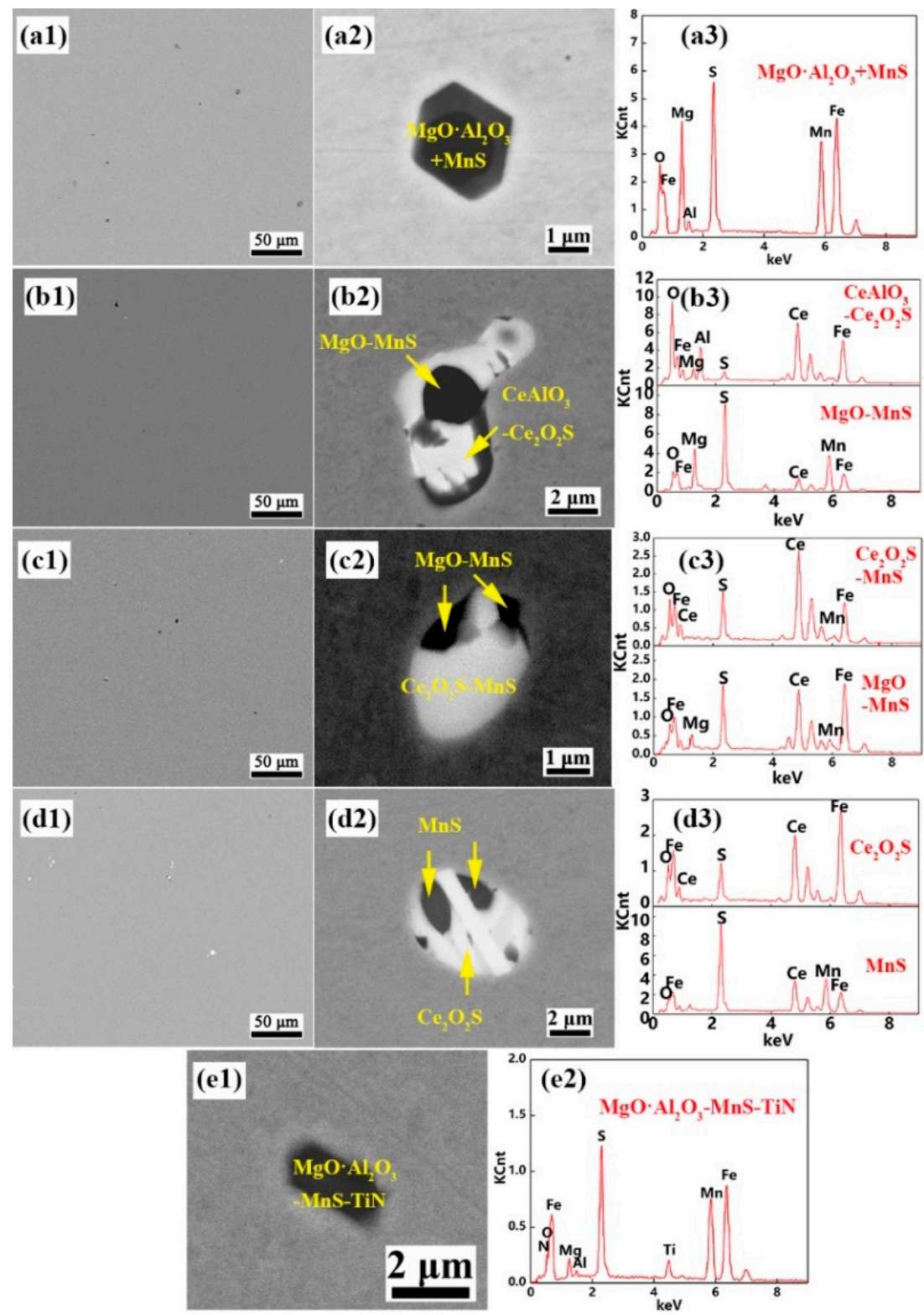

Figure 6. Typical inclusions in the as-cast samples. (a1-a3) \#1 (Ce-free); (b1-b3) \#2 (0.014\% Ce); (c1-c3) \#3 (0.024\% Ce); (d1-d3) \#4 (0.037\% Ce) and (e1,e2) TiN-containing inclusions in the Steel \#1.

Size distribution of inclusions in the melts is shown in Figure 7a. It clearly showed that majority of inclusions in the melts concentrated in the range of less than $2 \mu \mathrm{m}$. The size distribution of inclusions in the melts was little changed with the content of Ce increasing from 0 to $0.024 \%$. Nevertheless, when Ce content in the melt reached $0.037 \%$, the number density of inclusions less than $2 \mu \mathrm{m}$ obviously increased. In fact, a larger number of small spherical pure $\mathrm{Ce}_{2} \mathrm{O}_{2} \mathrm{~S}$ were found in the melt treated by $0.037 \% \mathrm{Ce}$. One of the potential reasons for this phenomenon is that these inclusions in the melt treated by $0.037 \%$ Ce formed spontaneously. The excessive addition of Ce makes a large amount of Ce-containing inclusions precipitate in a homogenous nucleation form, causing the inclusions in the melt to significantly increase. The interaction between the inclusions increased accordingly, further affecting the size and distribution of inclusions in the final quenched samples. 

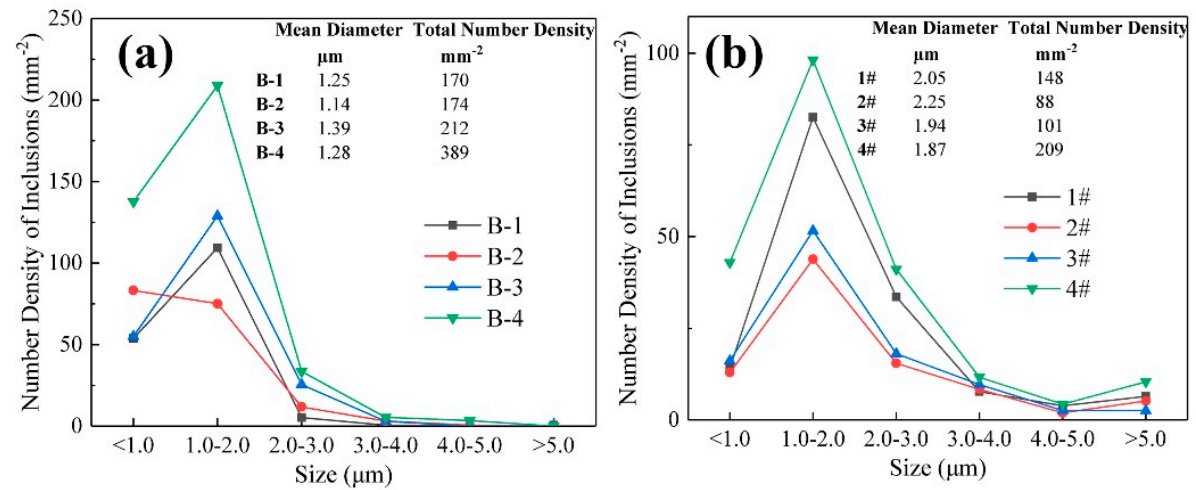

Figure 7. Size distribution of inclusions in the (a) melts and (b) as-cast samples.

It clearly shows in Figure $7 \mathrm{~b}$ that compared with the number density of inclusions in the melts (Figure 7a), the value in the final quenched samples \#1,\#2,\#3 and \#4 reduced by about $22 \mathrm{~mm}^{-2}$, $86 \mathrm{~mm}^{-2}, 111 \mathrm{~mm}^{-2}$ and $180 \mathrm{~mm}^{-2}$, respectively. Ce addition significantly reduced the number density of inclusions and improved the cleanliness of molten steel. It is worth noting that as the Ce content reached $0.037 \%$, a large amount of Ce was removed from the molten steel in the form of inclusions, which is not conducive to the full utilization of Ce in the steels.

\subsection{Microstructure of Tested Steels}

As shown in Figure 8, the types of microstructure in all tested steels were mainly polygonal ferrite (PF), ferrite side plate (FSP) and AF. In Steel \#1, a large amount of PF, FSP and a small number of AF were observed. The PF grains in Steel \#1 were coarse and distributed unevenly. The amount of AF in Steel \#2 increased and that of FSP decreased. With the addition of $0.024 \% \mathrm{Ce}$, the fraction of AF in Steel \#3 increased further and the PF distributed evenly. The microstructure in Steel \#3 was refined as shown in Figure 8c. Further addition of Ce caused an increase of FSP in Steel \#4 and the amount of AF and PF reduced.

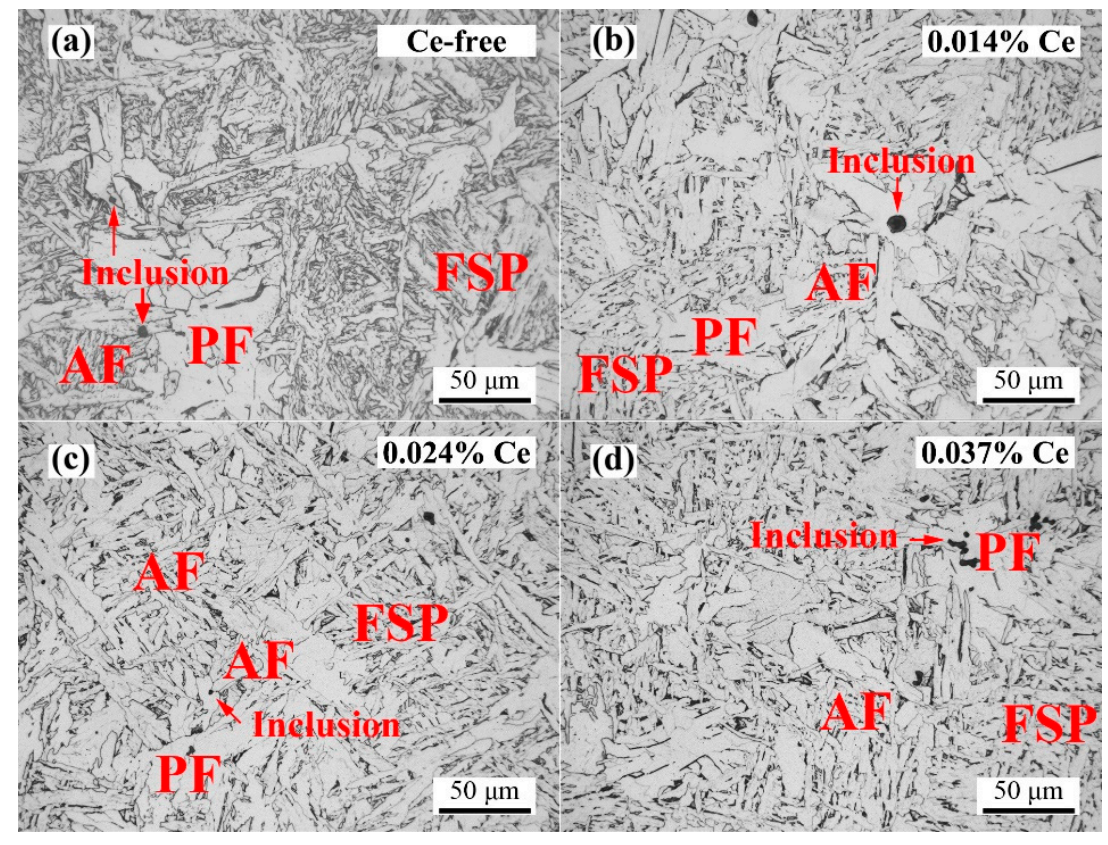

Figure 8. Microstructure of tested steels. (a) \#1; (b) \#2; (c) \#3 and (d) \#4.

EBSD results (Figure 9) showed that the ratio of High angle grain boundaries (HAGBs) in tested steels changed with Ce content. The ratio of HAGBs in the Steel \#1, \#2, \#3 and \#4was $17.40 \%, 17.52 \%$, 
$22.10 \%$ and $16.43 \%$, respectively. The Steel \#3 with highest amount of AF had the highest content of HAGBs among tested steels. The HAGBs were generally regarded as an important indicator of steel with good toughness due to its effect of inhibiting cracks propagation [24]. Further research concerning the effect of the Ce addition on the property of steel needs to be performed.

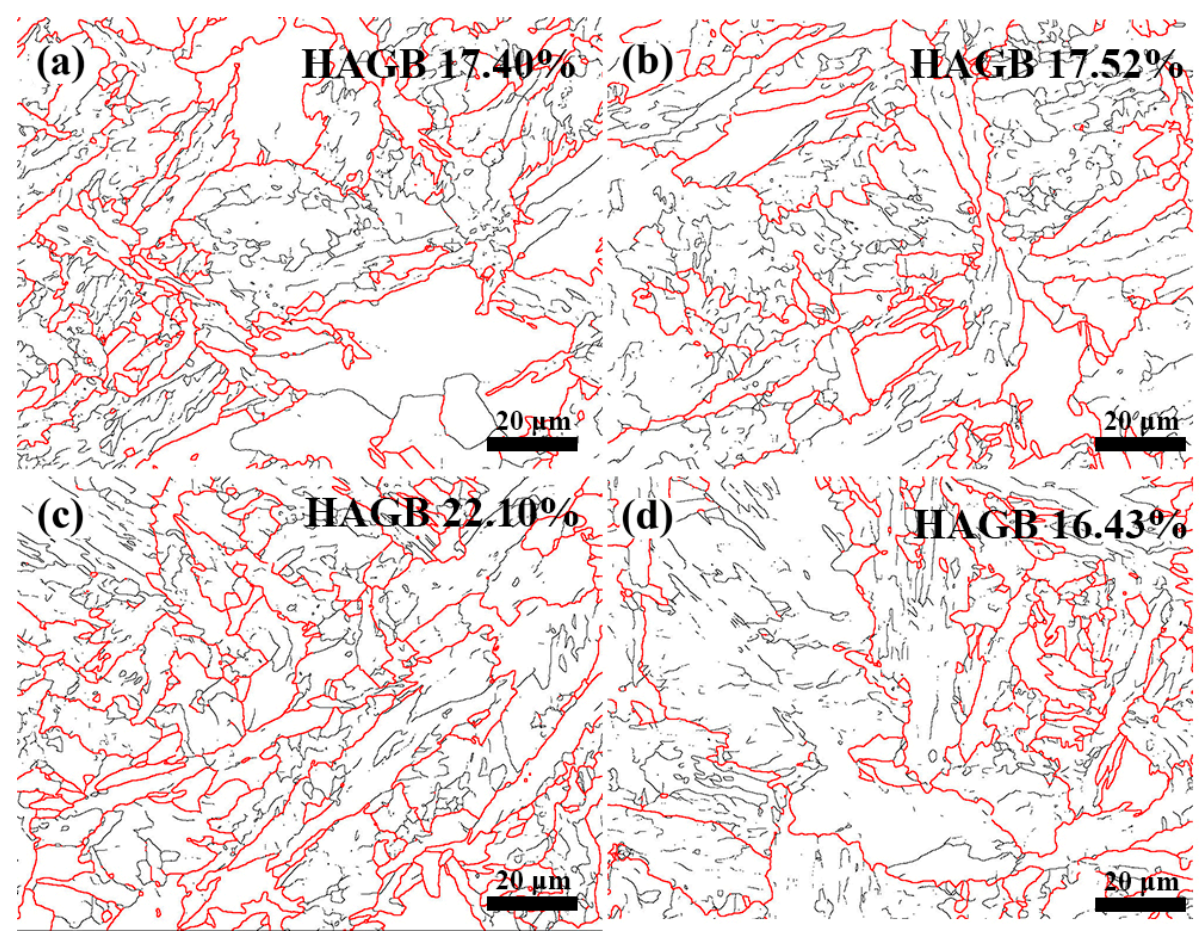

Figure 9. Morphology of the grain boundaries in tested steels. (a) \#1 (Ce-free); (b) \#2 (0.014\% Ce); (c) \#3 $(0.024 \% \mathrm{Ce})$; (d) \#4 $(0.037 \% \mathrm{Ce})$. Where the red line refers to the high angle grain boundary with grain misorientation more than $15^{\circ}$ and grey line refers to the low angle grain boundary with grain misorientation less than $15^{\circ}$.

\subsection{Composition, Size and Number Density of Effective Inclusions}

The results shown in Figure 10 indicated that the main types of inclusions, $\mathrm{MgO} \cdot \mathrm{Al}_{2} \mathrm{O}_{3}-\mathrm{MnS}$, $\mathrm{CeAlO}_{3}-\mathrm{MgO}-\mathrm{MnS}, \mathrm{Ce}_{2} \mathrm{O}_{2} \mathrm{~S}-\mathrm{MgO}-\mathrm{MnS}$ and $\mathrm{Ce}_{2} \mathrm{O}_{2} \mathrm{~S}-\mathrm{MnS}$ induced AF nucleation in Steel \#1, \#2, \#3 and \#4, respectively. This result explained why AF was found in all tested steels. However, pure MnS was not able to promote AF nucleating around the inclusions (Figure 10(b1,b2)), which was in agreement with the previous literatures $[25,26]$. In addition, densely distributed $\mathrm{Ce}_{2} \mathrm{O}_{2} \mathrm{~S}-\mathrm{MgO}$ was also not the effective inclusions in the steels (Figure 10(f1,f2)). This type of inclusion tended to distribute among grain boundaries and played no part in the nucleation of AF. Moreover, AF was found around the TiN-containing inclusions in the steels as shown in Figure 10(g1,g2).

The nucleation kinetics of AF was greatly affected by the energy balance of the interphase boundary among $\alpha$-Fe, inclusions and $\gamma$-Fe [27]. Good coherence between inclusions and $\alpha$-Fe leads to a decrease of the resistance of AF nucleation on inclusions [28]. AF tends to nucleate on the inclusions with low lattice mismatch against $\alpha$-Fe. The lattice mismatch of TiN, $\mathrm{MgO} \cdot \mathrm{Al}_{2} \mathrm{O}_{3}, \mathrm{MgO}, \mathrm{CeAlO}_{3}$ and $\mathrm{Ce}_{2} \mathrm{O}_{2} \mathrm{~S}$ with $\alpha$-Fe were 3.9\% [29], 0.6\% [30], 4.0\% [13], 7.25\% [20] and 1.9\% [31], respectively, which were in favor of AF nucleation. However, the lattice mismatch between MnS and $\alpha$-Fe was 8.9\% [30], causing pure MnS to not act as the nucleus of AF nucleation. 

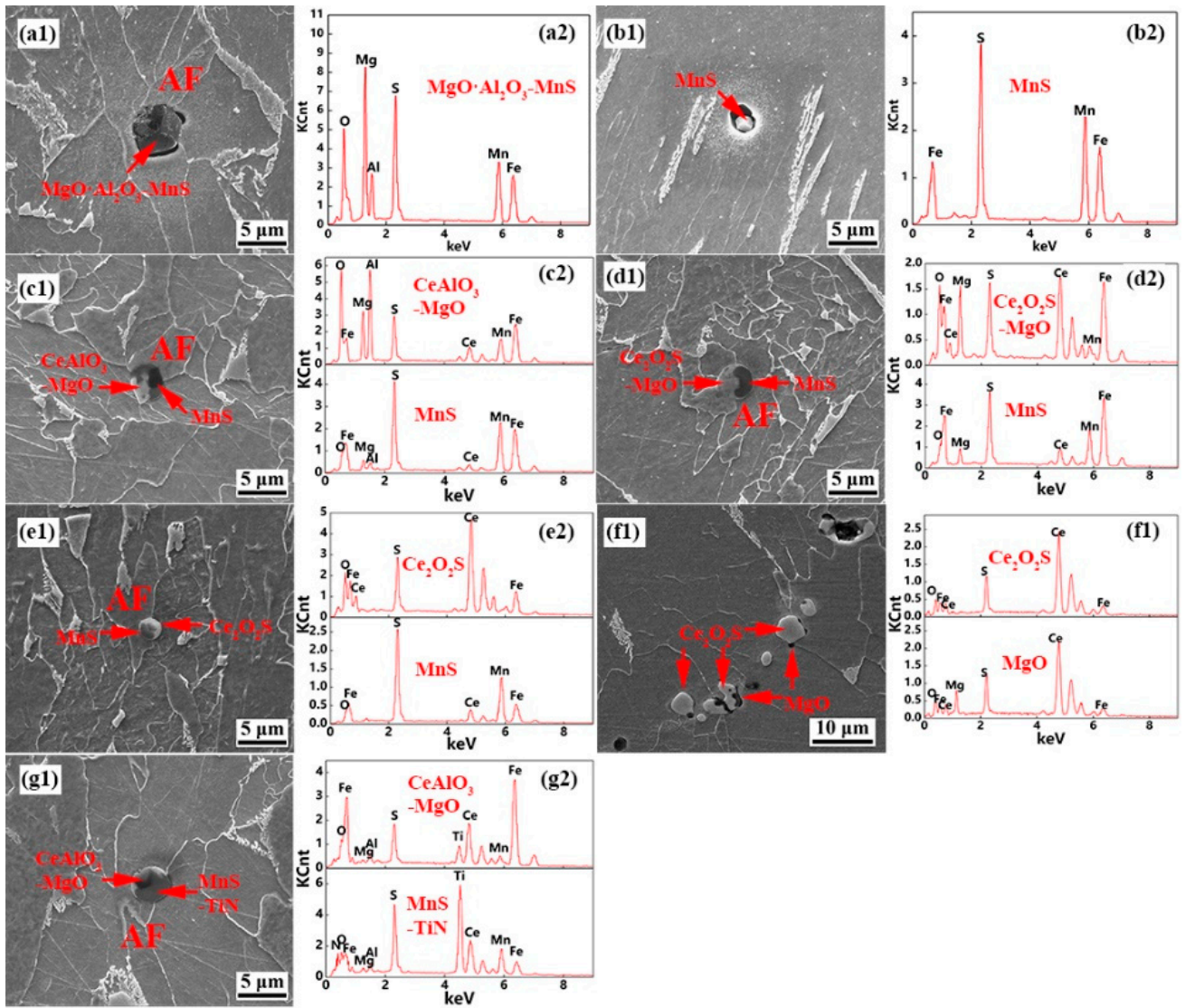

Figure 10. Morphology of acicular ferrite (AF) induced by main types of inclusions in the steel. (a1,a2,b1,b2) \#1 (Ce-free); (c1,c2) \#2 (0.014\% Ce); (d1,d2) \#3(0.024\% Ce); (e1,e2,f1,f2) \#4 $(0.037 \%$ Ce) and $(\mathbf{g} 1, \mathbf{g} 2)$ TiN-containing inclusion in Steel \#2.

Size distribution and number density of the effective inclusions in 100 randomly selected OM photos were analyzed based on the pointing counting method as depicted in Figure 11. It clearly showed that inclusions over $2.0 \mu \mathrm{m}$ seemed to be more effective in AF formation than the smaller ones, since more than $75 \%$ of effective inclusions in tested steels concentrated in the range of more than $2.0 \mu \mathrm{m}$, while the inclusions within the same size range in the as-cast samples accounted for only $35 \%$ of total inclusions (Figure $7 \mathrm{~b}$ ). In the Ce-free steel, 3.0-4.0 $\mu \mathrm{m}$ inclusions was most effective in promoting AF nucleation and the size of the most effective inclusions in Ce-treated steels decreased to $2.0-3.0 \mu \mathrm{m}$. For the mean size of effective inclusions, it decreased from $3.64 \mu \mathrm{m}$ to $3.22 \mu \mathrm{m}$ as the Ce content increased from 0 to $0.024 \% .0 .037 \%$ Ce in the steel contributed to a rise of the value to $3.68 \mu \mathrm{m}$. The size of effective inclusions in the steel with $0.024 \%$ Ce was smaller than those in other tested steels.

Brief summary, the distribution of inclusions in Steel \#3 was more dispersed than that of Steel \#4. Meanwhile, the number density of pure MnS was lower than that of Steel \#1 and \#2. Pure MnS was inert for the nucleation of AF in the current study. However, low mismatch between $\alpha$-Fe and Ce-containing inclusions enabled these inclusions to work as the nucleus of AF formation in the steel. Therefore, the highest number density of effective inclusions was achieved in Steel \#3 among other tested steels as shown in Figure 11. 


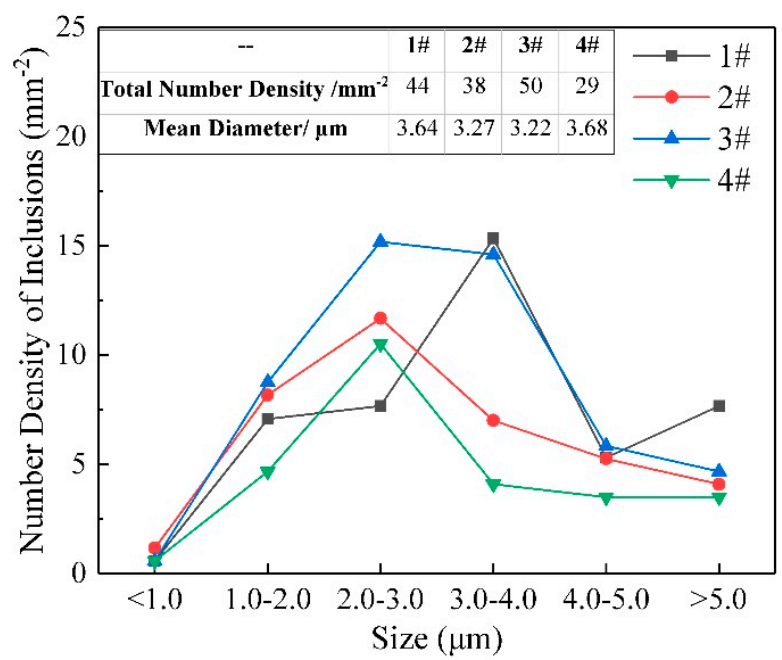

Figure 11. Size distribution of effective inclusions in the as-cast Steel \#1 (Ce-free); \#2 (0.014\% Ce); \#3 (0.024\% Ce) and \#4 (0.037\% Ce).

\section{Conclusions}

(1) The main types of inclusions changed from $\mathrm{MgO} \cdot \mathrm{Al}_{2} \mathrm{O}_{3}-\mathrm{MnS}$ to $\mathrm{CeAlO}_{3}-\mathrm{MgO}-\mathrm{MnS}$, $\mathrm{Ce}_{2} \mathrm{O}_{2} \mathrm{~S}-\mathrm{MgO}-\mathrm{MnS}$ and $\mathrm{Ce}_{2} \mathrm{O}_{2} \mathrm{~S}-\mathrm{MnS}$ after $0.014 \%, 0.024 \%$ and $0.037 \%$ Ce were added into the steels, respectively. The precipitation of pure MnS was suppressed with the addition of $0.024 \% \mathrm{Ce}$ due to the strong desulfurization capacity of $\mathrm{Ce}$. A large amount of $\mathrm{Ce}_{2} \mathrm{O}_{2} \mathrm{~S}$ formed in the steel with $0.037 \% \mathrm{Ce}$, causing the inclusions in the melts and the as-cast sample to distribute densely.

(2) The microstructure of tested steels was composed of AF, PF and FSP. When the Ce content increased from 0 to $0.024 \%$, the ratio of AF in the steels increased and PF distributed evenly. Excessive Ce in the steel contributed to a rise of FSP.

(3) The main types of inclusions in tested steels worked as the nucleus of the AF nucleation. Because of the comprehensive effects of a lower number of pure MnS, the dispersed distribution of inclusions and good coherence between the inclusions and $\alpha-\mathrm{Fe}$, the highest number density of effective inclusions was achieved in the steel with $0.024 \%$ Ce among the tested steels.

Supplementary Materials: The following are available online at http://www.mdpi.com/2075-4701/10/7/863/s1, Table S1: Chemical composition of tested steels for calculation/\%, Table S2: First order interaction coefficients of elements in $1873 \mathrm{~K}$, Table S3: Chemical equation of reaction $(\Delta \mathrm{G} \theta=\mathrm{A}+\mathrm{BT})[16,19]$, Table S4: Activity coefficients of elements in $1873 \mathrm{~K}$.

Author Contributions: Conceptualization, B.S.; Data curation, Z.L.; Formal analysis, Z.L.; Funding acquisition, B.S.; Investigation, Z.L.; Methodology, Z.L.; Project administration, Z.L. and B.S.; Resources, B.S.; Supervision, B.S.; Validation, Z.L., B.S. and Z.Y.; Visualization, Z.L; Writing—original draft, Z.L.; Writing-review \& editing, Z.L., B.S., Z.Y., X.C., L.L., L.W. and Z.S. All authors have read and agreed to the published version of the manuscript.

Funding: This research was funded by National Natural Science Foundation of China (grant No.51774024).

Conflicts of Interest: The authors declare no conflicts of interest.

\section{References}

1. Shome, M.; Gupta, O.P.; Mohanty, O.N. A Modified Analytical Approach for Modelling Grain Growth in the Coarse Grain HAZ of HSLA Steels. Scr. Mater. 2004, 50, 1007-1010. [CrossRef]

2. Cao, R.; Li, J.; Liu, D.S.; Ma, J.Y.; Chen, J.H. Micromechanism of Decrease of Impact Toughness in Coarse-Grain Heat-Affected Zone of HSLA Steel with Increasing Welding Heat Input. Metall. Mater. Trans. A 2015, 46, 2999-3014. [CrossRef]

3. Kitani, Y.; Ikeda, R.; Yasuda, K.; Oi, K.; Ichimiya, K. Improvement of HAZ Toughness for High Heat Input Welding by using Boron Diffusion from Weld Metal. Weld. World 2007, 51, 31-36. [CrossRef] 
4. Kundu, A. Austenite Grain Boundary Pinning during Reheating by Mixed AlN and $\mathrm{Nb}(\mathrm{C}, \mathrm{N})$ Particles. ISIJ Int. 2014, 54, 677-684. [CrossRef]

5. Mizoguchi, S.; Takamura, J. Control of Oxides as Inoculants. In Proceedings of the 6th International Iron and Steel Congress, ISIJ, Nagoya, Japan, 21-26 October 1990; The Iron and Steel Institute of Japan: Tokyo, Japan, 1989.

6. Takemura, J.; Mizoguchi, S. Roles of Oxides in Steel Performance. In Proceedings of the 6th International Iron and Steel Congress, ISIJ, Nagoya, Japan, 21-26 October 1990; The Iron and Steel Institute of Japan: Tokyo, Japan, 1989.

7. Sarma, D.S.; Karasev, A.V.; Jonsson, P.G. On the Role of Non-metallic Inclusions in the Nucleation of Acicular Ferrite in Steels. ISIJ Int. 2009, 49, 1063-1074. [CrossRef]

8. Sun, J.; Zou, X.; Matsuura, H.; Wang, C. Effect of Heat Input on Inclusion Evolution Behavior in Heat-Affected Zone of EH36 Shipbuilding Steel. JOM 2018, 70, 946-950. [CrossRef]

9. Zou, X.; Zhao, D.; Sun, J.; Wang, C.; Matsuura, H. An Integrated Study on the Evolution of Inclusions in EH36 Shipbuilding Steel with Mg Addition: From Casting to Welding. Metall. Mater. Trans. B 2018, 49, 481-489. [CrossRef]

10. Zou, X.; Sun, J.; Matsuura, H.; Wang, C. In Situ Observation of the Nucleation and Growth of Ferrite Laths in the Heat-Affected Zone of EH36-Mg Shipbuilding Steel Subjected to Different Heat Inputs. Metall. Mater. Trans. B 2018, 49, 2168-2173. [CrossRef]

11. Zhang, C.; Gao, L.; Zhu, L. Effect of Inclusion Size and Type on the Nucleation of Acicular Ferrite in High Strength Ship Plate Steel. ISIJ Int. 2018, 58, 965-969. [CrossRef]

12. Chai, F.; Yang, C.; Su, H.; Zhang, Y.; Xu, Z. Effect of Magnesium on Inclusion Formation in Ti-killed Steels and Microstructural Evolution in Welding Induced Coarse-grained Heat Affected Zone. J. Iron Steel Res. Int. 2009, 16, 69-74. [CrossRef]

13. Song, M.; Song, B.; Hu, C.; Xin, W.; Song, G. Formation of Acicular Ferrite in Mg Treated Ti-bearing C-Mn Steel. ISIJ Int. 2015, 55, 1468-1473. [CrossRef]

14. Kong, H.; Lin, H.; Yue, Q.; Cai, Z. Effects of Ti-Mg Complex Inclusions on Acicular Ferrite Nucleation. High Temp. Mater. Process. 2017, 36, 459-465. [CrossRef]

15. Lou, H.; Wang, C.; Wang, B.; Wang, Z.; Li, Y.; Chen, Z. Inclusion Evolution Behavior of Ti-Mg Oxide Metallurgy Steel and Its Effect on a High Heat Input Welding HAZ. Metals 2018, 8, 534. [CrossRef]

16. Zhang, T.; Wang, D.; Liu, C.; Jiang, M.; Lv, M.; Wang, B.; Zhang, S. Modification of Inclusions in Liquid Iron by $\mathrm{Mg}$ Treatment. J. Iron Steel Res. Int. 2014, 21, 99-103. [CrossRef]

17. Cha, W.; Nagasaka, T.; Miki, T.; Sasak, Y.; Hino, M. Equilibrium between titanium and oxygen in liquid Fe-Ti alloy coexisted with titanium oxides at $1873 \mathrm{~K}$. ISIJ Int. 2006, 46, 996-1005. [CrossRef]

18. Wang, Q.; Zou, X.; Matsuura, H.; Wang, C. Evolution of Inclusions During 1473 K Heating Process in EH36 Shipbuilding Steel with Mg Addition. JOM 2018, 70, 521-526. [CrossRef]

19. Adabavazeh, Z.; Hwang, W.S.; Su, Y.H. Effect of Adding Cerium on Microstructure and morphology of Ce-Based Inclusion Formed in Low-Carbon Steel. Sci. Rep. 2017, 7, 1-10. [CrossRef]

20. Song, M.; Song, B.; Xin, W.; Sun, G.; Song, G.; Hu, C. Effects of Rare Earth Addition on Microstructure of C-Mn Steel. Ironmak. Steelmak. 2015, 42, 594-599. [CrossRef]

21. Appelberg, J.; Nakajima, K.; Shibata, H.; Tilliander, A.; Jönsson, P. In Situ Studies of Misch-metal Particle Behavior on a Molten Stainless Steel Surface. Mater. Sci. Eng. A 2008, 495, 330-334. [CrossRef]

22. Brarin, I.; Knacke, O.; Kubaschewski, O. Thermochemical Properties of Inorganic Substances, 1st ed.; Springer: Berlin/Heidelberg, Germany, 1977; pp. 159-162. [CrossRef]

23. Ren, Q.; Zhang, L. Effect of Cerium Content on Inclusions in an Ultra-Low-Carbon Aluminum-Killed Steel. Metall. Mater. Trans. B 2020, 51, 589-600. [CrossRef]

24. Díaz-Fuentes, M.; Iza-Mendia, A.; Gutiérrez, I. Analysis of Different Acicular Ferrite Microstructures in Low-carbon Steels by Electron Backscattered Diffraction. Study of Their Toughness Behavior. Metall. Mater. Trans. A 2003, 34, 2505-2516. [CrossRef]

25. Deng, X.; Jiang, M.; Wang, X. Mechanisms of Inclusion Evolution and Intra-granular Acicular Ferrite Formation in Steels Containing Rare Earth Elements. Acta Metall. Sin. (Engl. Lett.) 2012, 25, 241-248. [CrossRef]

26. Shim, J.; Oh, Y.; Suh, J.; Cho, Y.; Shim, J.; Byun, J.; Lee, D. Ferrite Nucleation Potency of Non-metallic Inclusions in Medium Carbon Steels. Acta Mater. 2001, 49, 2115-2122. [CrossRef] 
27. Furuhara, T.; Shinyoshi, T.; Miyamoto, G.; Yamaguchi, J.; Sugita, N.; Kimura, N.; Takemura, N.; Maki, T. Multiphase Crystallography in the Nucleation of Intragranular Ferrite on MnS+V(C, N) Complex Precipitate in Austenite. ISIJ Int. 2003, 12, 2028-2037. [CrossRef]

28. Babu, S.S. The Mechanism of Acicular Ferrite in Weld Deposits. Curr. Opin. Solid State Mater. Sci. 2004, 8, 267-278. [CrossRef]

29. Bramfitt, L.B. The Effect of Carbide and Nitride Additions on the Heterogeneous Nucleation Behavior of Liquid Iron. Metall. Trans. 1970, 1, 1987-1995. [CrossRef]

30. Wen, B.; Song, B.; Pan, N.; Hu, Q.Y.; Mao, J.H. Effect of SiMg alloy on inclusions and microstructures of $16 \mathrm{Mn}$ steel. Ironmak. Steelmak. 2011, 38, 577-583. [CrossRef]

31. Wen, B.; Song, B.; Pan, N.; Hu, Q.; Mao, J. Effect of Austenitizing Temperature on Microstructure in 16Mn Steel Treated by Cerium. Int. J. Miner. Metall. Mater. 2011, 18, 652-658. [CrossRef]

(C) 2020 by the authors. Licensee MDPI, Basel, Switzerland. This article is an open access article distributed under the terms and conditions of the Creative Commons Attribution (CC BY) license (http://creativecommons.org/licenses/by/4.0/). 